\title{
Is E-Learning for Primary School Students During the COVID-19 Pandemic a Boon or Bane?
}

Sukanta Chandra Swain, KIIT University (Deemed), Odisha, India

\begin{abstract}
In order to connect with the students during the lockdown and shutdown owing to the COVID-19 pandemic, the primary education system of India has adopted virtual platforms. As such, the stakeholders of the primary education system in India were not technology savvy enough to adopt virtual platforms for teaching and learning. It is pertinent to unfold the journey of the important stakeholders of primary education (i.e., teachers, students, and parents in the process of using virtual platforms during current pandemic). Thus, the objective of this paper is to establish on the basis of personal interviews among 50 parents of primary school students and 30 primary school teachers whether teaching and learning in virtual platforms happened to be a boon or bane in primary education in India. It is found that mandating e-learning for the teachers and students has more cons for all the stakeholders of the primary education.
\end{abstract}

\section{KEYWORDS}

Addiction, COVID-19, E-Learning, Health Issues, Lock-Down, Pandemic, Primary Education

\section{INTRODUCTION}

Covid-19 pandemic has made the world stand-still on its path of development. All the sectors and all the communities of the globe has been affected so badly that if the pandemic ends now, it will take years to catch the momentum that they were experiencing in their usual functioning prior to the outbreak of the pandemic. As such, there is no hope of the pandemic getting ended now and hence recovery from damages by the pandemic, which have been intensified day by day, may need a very extended time frame. Two sectors of any economy that matter most are education and health. Pandemic has distorted the health sectors directly as multiple lakhs of people are becoming prey of the deadly virus. Education sector is devastated indirectly as to check the spread of Covid-19, all the educational institutions are closed, examinations of the ongoing Semesters/Terms are postponed indefinitely and evaluation process of the classes for which examinations are completed has not been started yet. Commencement of new Sessions will be delayed indefinitely. Private educational institutions will suffer a lot as they are unable to generate revenue either from fresh admission or from the existing students' Semester fee payments. Consequently, the promoters of the private educational 
institutions are paying the employees either less than what they deserve or not paying at all. In short, the education sector of the country has been immensely suffered.

Pandemic due to the deadly virus Covid-19 has put the entire world in complete lock-down, that too, for months together. India has locked-down the entire country for more than two months. Schools, Colleges and Universities were to be closed immediately putting everything in halt. Classes were abruptly suspended and examinations were to be postponed indefinitely. Education at all levels got affected hugely. Higher education institutes (HEIs) of India that are embedded with technology blend teaching-learning system, used electronic mode for teaching and learning, i.e., e-learning, immediately after the announcement of first phase of lock-down. Following the trend, some of the primary Schools of the country also adopted the virtual platform for teaching-learning. On this backdrop, it is necessary to unfold whether the stakeholders of primary education are ready for virtual platform of teaching-learning.

Covid-19 pandemic has forced India to lock-down the country in different phases for the sake of social distancing. Planners and decision makers were expecting that the lock down will get over in a week or so and thereafter all academic activities will be resumed. But that did not happen. Lockdown got extended in India in four phases for more than two months. Nobody knows whether this will be extended further. Keeping this in mind, most of the higher educational institutions have adopted e-learning platform to complete the syllabi and conduct examinations. Even at school level, the classes, which will have Board/Council examinations in this academic year, have also been dragged into the purview of e-learning platform. In Odisha, Classes of Vernacular schools other than $10^{\text {th }}$ Class are excluded from virtual learning platform. However, the teachers of those classes are instructed to reach out to the students' residence and distribute books to them as they don't have books for new classes and book shops are closed due to lock-down.

But the exceptional practice that happened during this pandemic is exposing primary school students to e-learning platform. Of course, this e-learning platform has not been adopted by primary vernacular schools. Government Schools have not sought for that but some of the private schools, for say in Odisha, have been utilizing virtual platform for teaching-learning even in primary classes. However, it is yet to ascertain to what extent the e-learning is beneficial or hazardous to the stakeholders of the primary schools, specifically to the students of primary schools. This is the base of this paper.

The plan of this paper is as follows. Section-2 of the paper outlines the conceptual framework of the study. Objectives and Methodology of the study is presented in Section-3. Section-4 explains different virtual learning/E-learning modes practiced at primary education level during Covid-19 pandemic. Data collected from the stakeholders of primary education have been analyzed in Section-5. Section-6 summarizes the findings of the study and Conclusion is presented in Section-7.

\section{CONCEPTUAL FRAMEWORK}

Hellsten (2006) in his case study reveals that Information Technology has been experienced as an innovative and conducive tool for enhancing teaching and learning. Although the pedagogical transformation to be fitted for virtual teaching-learning platform needs more concerted efforts and elongated time of the teachers, considering the inherent benefits of the tool, teachers could follow. It is also revealed by the researcher that adopting e-learning platform is more difficult for the lady teachers as compared to the gents teachers. Etherington (2008) unwraps the gray areas of e-learning. For primary students, e-learning is not conducive as it creates various problems like homogenization and dehumanization which leads to 'McDonaldization of education'. Chen et al. (2004) presents that for quality in e-learning what matters most is satisfaction of learners. Identifying the factors that satisfy the learners or dissatisfy them is crucial as it will strengthen the quality of e-learning mode. Out of four critical incidents that affect the satisfaction level of e-learning; administration, functionality, instruction and interaction, two most important critical incidents are interaction and functionality. 
Sung et al. (2016) find the use of mobile devices like smart phone, tablet and laptop in teachinglearning is better than the use of desktop computers or not using any mobile devices. It is also found that the effect is more for devices in hand than for laptops, for inquiry-oriented learning than lectures, for informal educational environment than their formal counterparts, and for short-duration interventions than long-term interventions. While existing literature on mobile technologies in learning focus on issues pertaining to technology and usage, Huang et al. (2020) focus on student learning beliefs on intentions of University students to use mobile technology in learning in China and Spain. They find that learning with the help of mobile technologies has its advantages for catering knowledge to learners at their convenience both in formal and informal ways. Still the acceptance of mobile technologies is in its nascent stage.

Terms and conditions involved in Learning Management Systems (LMSs) are a sort of one-way contract as the users don't have anything to do except either to accept or decline. Thus, the probability of the usage of fake identity on the part of the users is very high. Amo et al. (2020) studied students and teachers to corroborate the practicability and approval of using fake name to anonymize their identification in LMSs as a sustainable solution to the problem. Considering the affirmative outcome, they formulated a user-friendly plugin for Moodle that enables students' identity anonymization by the use of aliases. Considering the security issues in cloud computing, Stergiou et al. (2018) proposed a new integrated system having the blend of Cloud Computing and Internet of Things as a base setting for Big Data. Moreover, they projected a solution for installation of a security "wall" between the Cloud Server and the Internet, with the intent to obviate the privacy and security issues. Based on numerical studies, Al-Qerem et al. (2020) assessed the partial substantiation process under three concurrence codes of conduct. The results of the study inform that employing the projected mechanism shall yield advantages for IoT users. These advantages are obtained from transactional services. They found that the projected mechanism shall enable low-latency fog computing services of the IoT applications that have time-lag sensitivity.

From the existing literature, it is found that the use of e-learning platform has mixed impact both positive and negative. For primary education, it has never been researched whether e-learning is beneficial or not for stakeholders of primary education, if it is the only mode of teaching-learning. However, there is research on the use of e-learning as supplement to classroom teaching-learning at primary level which found that the impact is mixed. Considering this, the status of e-learning as the only mode of teaching-learning at primary education level during Covid-19 pandemic has been picked up for this study.

During the initial phases of lock down owing to Covid-19 pandemic, as the examinations in Schools were not completed, the Boards decided to promote the students to their next classes automatically either without examinations or without result if examinations were completed, except the classes with Board examination, i.e., $10^{\text {th }}$ and $12^{\text {th }}$ classes. By the time, the third phase of lock down was about to be implemented, primary schools also felt the necessity of connecting to the students and cover the Syllabi. Accordingly, they instructed to their teachers to connect to the students with social media and have meetings with them and their parents through online free meeting platforms like ZOOM Meetings, Cisco Webex Meetings, Google Meet, etc. in order to cover first few chapters of each subject of the promoted classes. The teachers who were not that technology savvy could manage to cope as they learned from here and there because of the fear of losing the jobs. However, as most of them were using the technology for the first time, they were not confident whether they could succeed. But the real problem remain with the learners. For knowing whether e-learning for primary school students during Covid-19 pandemic is a boon or bane, the study is confined to primary schools of Odisha state of India.

E-learning is a network enabled platform through which delivery of education can be made to a larger audience virtually. In fact, without physical presence, the learners can get the necessary skills and knowledge from the teachers/trainers even staying at their homes. Only thing they need at 
their homes for this purpose is a device with internet connectivity. The device could be Computer or smart phone.

On e-learning platform, the learners in primary education has multiple issues. The most important three issues are shown below.

\subsection{The Most Important Issue is Pertaining to the Feasibility, i.e., is it so That All Primary Students of Odisha have the Accessibility of a Smart Phone or Computer With Internet Connectivity}

Shifting education to online mode has been a point of discussion for quite some time. People have mixed reactions on this shift. E-learning during Covid-19 pandemic has been the talk of every aspect of society as educational institutes at all levels have been trying to implement in the system so as to connect with the students and not to lag in academic coverage vis-a-vis time. However, the UNESCO has given a global perspective to unwrap the concern pertaining to the shift towards virtual platform that has been adopted to educational discontinuity. As per its statistics, about $50 \%$ of the learners, i.e., some 82.6 crore students out of the classroom because of the pandemic do not have computers at their home and about $43 \%$ of the learners, i.e., some 70.6 crore students are not able to access the internet at their homes. Odisha being one of the poorest states of India and having a greater junk of poor population of the country, the figures on having computer or smart phone with internet connectivity are much behind that is mentioned by the UNESCO. In such a situation, feasibility of transferring physical learning to virtual learning is a big question.

There is no doubt that during complete lock-down, if teachers can reach to students at their homes virtually, it will help them a lot as they won't lose anything in their academic calendar. However, educational experts don't see it favorably as they could foresee the concerns inherent in it. Digital shift of teaching-learning has multiple concerns among those two important ones are; 1) In this process, young children are highly exposed to internet, that too, for longer period with the support from the parents and teachers, which has high potential for endangering the career of the children, and 2) Due to digital shift, economically underprivileged students, who don't have devices and connectivity that are required of e-learning, may get alienated.

\subsection{The Second Important Issue is Related to the Health of the Children}

Digital shift of education during Covid-19 pandemic is not free from health related issues of young children. As said by the UNICEF, due to e-learning platform, young students are staying online most of the time during lock-down owing to the pandemic. Remaining online most of the time makes the lives of the young children prone to harms. Similarly, the National Institute of Mental Health and Neurosciences (NIMHANS) states that young students' mental health is at stake as they are increasingly depending on gadgets during lock-down owing to Covid-19 pandemic. In fact, the young children are simply finding them in front of the screens most of the time and they are deprived of the physical exercises what they were doing before the outbreak of the pandemic. This trend is alarming in true sense as it may have repercussions on mental status of the young children.

\subsection{The Third Important Issue is Pertaining to the Danger of Those Free Meeting Sites}

As such, internet is the storehouse many things that are constructive and destructive as well. Young minds are curious and hence they fall prey of unsocial things if they experience it once. Therefore, parents always caution their children for not using internet. But during the pandemic, the situation is completely different. We are insisting the young children to use internet and that too for longer duration on regular basis. Parents may not accompany the children every time they become online for learning. There are cyber assailants who look for this type of situations to victimize young minds sexually and train them many things that the children must not be know at their ages. As young children have the 
anxiety to know all those secret things and take the pleasure of doing all those forbidden acts, young children get groomed in wrong direction and cost their academic career.

However, to face all these adversities of e-learning, which is now every stakeholder's word in education system, the UNICEF has put forth many recommendations for all the stakeholders of education system. It advised to the government that the child protection services should be stringent and must be available around the clock so that any mishap can be detected immediately and miscreants will be punished fast. It also suggested to the parents of the young children for ensuring all updated soft-wares and anti-virus tools being installed in the devices that are used by their children.

\section{OBJECTIVES AND METHODOLOGY}

Whatever may be the situation, the fact is that the kids in primary classes are accessing the devices like Smart Phone or Desktop or Laptop for longer time on daily basis to participate in virtual teachinglearning process.

Under the circumstances of implementing e-learning in primary education, the objectives of this Paper are:

- To assess the pros and cons of e-learning for primary students of Odisha; and

- To establish whether e-learning is a boon or bane for primary students.

Methodology adopted for the objectives mentioned are as follows. It is a descriptive study done by mixed methods. Both qualitative and quantitative data have been used. The Study area is Bhubaneswar city, the Capital of Odisha State and it is selected for convenience owing to lock-down. The stakeholders of the primary education, particularly the students along with their parents and the teachers constitute the Universe of this study. Sample units are selected on the basis of convenience and referral sampling. For the purpose, 50 parents of primary School students, 20 primary school teachers from English medium schools and 10 primary school teachers from Odia medium Schools have been selected and studied. Data have been collected through direct personal interviews from the respondents who were accessible in person whereas, some respondents have been interviewed over telephone. Besides, experts' opinion have been considered. Data have been analyzed and presented through descriptive statistics, ANOVA and Multiple Regression.

\section{MODES OF VIRTUAL LEARNING/E-LEARNING PRACTICED DURING COVID-19 PANDEMIC}

During Covid-19 pandemic, to connect with the students and cover the stipulated portions of the curriculum, some primary educational institutes in Odisha have adopted e-learning platforms. However, all of those institutions are not practicing the same mode of e-learning. All the modes of e-learning practiced by the institutions during the pandemic are mentioned in this Section.

\subsection{Use of WhatsApp}

Some of the Schools in Odisha, particularly government Schools are using the WhatsApp for connecting with their students and covering Syllabus. All the class teachers are directed to create WhatsApp groups of the students of their respective classes. For this, parents of every student must have smart phones with internet connectivity all the time.

The class teachers are creating the WhatsApp groups of their students and adding all the teachers of that class in that group. Each teacher posts study materials of his/her subject in the group with proper direction. Teachers are posting assignments for the students with prescription of datelines. 
If any student finds any difficulty, s/he posts his/her queries on the group and respective teacher addresses to the queries.

\subsection{Sending Study Materials Through Email}

Some Schools in Odisha are using e-mail as the mode communicating with their students pertaining to studies. Teachers ask the parents to share their e-mail IDs to the class teachers. Class teachers send all the details of teaching-learning through e-mail with copy marked to all teachers of a class. Every teacher sends the study materials and assignments to the students through e-mail. However, responses through this mode is not instant and all the stakeholders of the system need to browse their inbox very frequently.

\subsection{Online Classes}

Good number of Schools in Odisha from primary education wing are conducting online classes for their students. The class teacher of each section is assigned the task of creating the group and communicate with all the students through the group concerning class schedules and modality of teaching. Schools are deciding the sites the teachers are to use for online classes. Mostly used Sites for online classes by the Schools are ZOOM, Cisco Webex, Google Class, and Moodle. All these sites are having free access with limited usage and paid access with extended facilities. Quality of service depends on the mode a particular school is preferring.

\subsection{Miscellaneous Modes}

There are some other modes followed in Odisha, which are not truly types of e-learning platforms but are means to connect to the students during Covid-19 pandemic in the absence of regular classes. Two important modes of such type are:

1. Sending teachers to the students to provide Books: It is happening in government vernacular schools. As per the directions of the government of Odisha, school teachers are visiting to the students' houses and providing them the books and study materials supplied by the government. Also, the amount that was spent on per head mid-day meals of such students is being transferred to their respective parents' accounts.

2. DTH Platforms: Initiatives are also taken both by Indian government and Odisha government exactly in line with virtual learning to use DTH platforms for making lessons available for the students.

The basic objective of all these modes of connecting to the students is to keep the students in study mode and avoid losing academics due to lock-down.

\section{DATA ANALYSIS}

For the study, 50 parents of primary school students were interviewed in line with a structured questionnaire to ascertain whether the e-learning platforms are beneficial for their children or not. The questionnaire administered was a blend of questions to capture quantitative data in a 5-point rating scale and qualitative data through some open-end questions. For data in rating scale, variables are identified on the basis of existing literature. Variables identified are: Overall provisions designed meet learner's need without any distortions (V1), Administrative service is of good quality (V2), Response time of virtual teaching-learning is good (V3), Virtual teaching-learning platform is stable (V4), Study materials do not meet learners' need (V5), Recorded lectures meet learners' need (V6), Recorded lecture is boring (V7), Study material is boring (V8), Learning activities designed are 
Table 1. Reliability Statistics

\begin{tabular}{|l|l|}
\hline \multicolumn{1}{|c|}{ Cronbach's Alpha } & \multicolumn{1}{c|}{ N of Items } \\
\hline 0.763 & 16 \\
\hline
\end{tabular}

Source: SPSS Output on the basis of Primary Data

good (V9), Assessment methods designed are good (V10), Adaptation of teaching method is bad (V11), Communication is up to mark and hence reaching group consensus is easy (V12), In spite of no physical interaction, misunderstanding is not there (V13), Interaction for class discussion is good (V14), Making children learn through Online classes/WhatsApp or E-mail communications doesn't put extra burden (V15), and There is no risk of becoming prey to the disadvantages of virtual world through this mode of teaching-learning (V16). V1, i.e., Overall provisions designed meet learner's need without any distortions is the dependent variable and V2 - V16 are independent variables.

\subsection{Reliability of Data}

For reliability of data Cronbach's Alpha was computed and found 0.763 as mentioned in Table 1. Since it is more than 0.7 , the data collected are reliable.

\subsection{ANOVA for Hypothesis Testing}

Null Hypothesis: Overall provisions designed in virtual learning (Online Classes and Communications through WhatsApp/E-mail) for primary school students don't meet the learner's need without any distortion.

For testing the null hypothesis, ANOVA was computed and presented in Table 2.

The p-value, as presented in $6^{\text {th }}$ Column of Table 2, is 0.062 and the level of significance (i.e., $\alpha$ ) is usually taken 0.05 for this type of research. Since the p-value is greater than the level of significance, we will accept the null hypothesis. Thus, it is inferred that overall provisions designed in virtual learning (Online Classes and Communications through WhatsApp/E-mail) for primary school students don't meet the learner's need without any distortion.

\subsection{Regression Analysis for Identifying the Variables that Matter}

In order to know the variables that significantly influence the satisfaction level of the primary school students on virtual learning (Online Classes and Communications through WhatsApp/E-mail), Regression coefficients are considered as presented in Table 3.

Out of 15 independent Variables, 'p' values for four variables V5 (Study materials do not meet learners' need), V11 (Adaptation of teaching method is bad), V13 (In spite of no physical interaction, misunderstanding is not there), and V14 (Interaction for class discussion is bad) are less than the ' $\alpha$ '

\section{Table 2. ANOVA ${ }^{a}$}

\begin{tabular}{|l|l|l|l|l|c|c|}
\hline \multicolumn{2}{|c|}{ Model } & \multicolumn{1}{c|}{ Sum of Squares } & df & Mean Square & F & Sig. \\
\hline \multirow{3}{*}{1} & Regression & 13.781 & 15 & .919 & 1.889 & $.062^{\mathrm{b}}$ \\
\cline { 2 - 7 } & Residual & 16.539 & 34 & .486 & & \\
\cline { 2 - 7 } & Total & 30.320 & 49 & & \\
\hline \multicolumn{2}{|l}{ a. Dependent Variable: V1 } \\
\multicolumn{2}{|l}{ b. Predictors: (Constant), V16, V6, V2, V14, V11, V4, V7, V15, V10, V9, V12, V3, V13, V5, V8 } \\
\hline
\end{tabular}

Source: SPSS Output on the basis of Primary Data 
Table 3. Regression Coefficients ${ }^{\mathrm{a}}$

\begin{tabular}{|c|c|c|c|c|c|c|}
\hline & Model & Unsta & d Coefficients & $\begin{array}{c}\text { Standardized } \\
\text { Coefficients }\end{array}$ & $\mathbf{t}$ & Sig. \\
\hline & & B & Std. Error & Beta & & \\
\hline & (Constant) & 7.540 & 1.568 & & 4.809 & .000 \\
\hline & $\mathrm{V} 2$ & .234 & .132 & .247 & 1.781 & .084 \\
\hline & V3 & .510 & .427 & .505 & 1.195 & .241 \\
\hline & V4 & .084 & .132 & .093 & .633 & .531 \\
\hline & V5 & -1.079 & .435 & -1.159 & -2.480 & .018 \\
\hline & V6 & -.192 & .282 & -.208 & -.681 & .500 \\
\hline & V7 & -.206 & .124 & -.315 & -1.658 & .107 \\
\hline 1 & V8 & .239 & .377 & .340 & .632 & .531 \\
\hline 1 & V9 & .157 & .310 & .187 & .505 & .617 \\
\hline & V10 & .140 & .179 & .162 & .783 & .439 \\
\hline & V11 & -.850 & .225 & -1.196 & -3.776 & .001 \\
\hline & V12 & .102 & .172 & .117 & .592 & .558 \\
\hline & V13 & .606 & .201 & 1.122 & 3.011 & .005 \\
\hline & V14 & -.638 & .295 & -.659 & -2.159 & .038 \\
\hline & V15 & .081 & .161 & .091 & .502 & .619 \\
\hline & V16 & -.137 & .152 & -.157 & -.904 & .372 \\
\hline
\end{tabular}

a. Dependent Variable: $\mathrm{V} 1$

Source: SPSS Output on the basis of Primary Data

value. Thus, these four independent variables significantly influence the dependent variable and the Regression Model is: V1 = 7.54 - 1.079V5 - 0.850V11 + 0.606V13 - 0.638V14.

Since the algebraic signs of coefficients of V5, V11, and V14 are negative, there is an inverse relationship between each of the variables with V1 (Overall provisions designed meet learner's need without any distortions). It means, if study materials do not meet learners' need (V5), overall provisions designed do not meet learner's need without any distortions and the vice versa. So also is the case for V11 and V14. If adaptation of teaching method is bad (V11), overall provisions designed do not meet learner's need without any distortions and the vice versa. Similarly, if interaction for class discussion is bad (V14), overall provisions designed do not meet learner's need without any distortions and the vice versa.

Another variable V13 has direct influence on V1. It means, if in spite of no physical interaction, misunderstanding is not there (V13), overall provisions designed meet learner's need without any distortions.

To know the level of impact of each independent variable on the dependent variable, the standardized regression coefficients (Beta) is to be considered. If the $\beta$ value of a variable is greater, the said variable influences the dependent variable more. As presented in Table $3, \beta$ value for four significant variables are: V5 $=-1.159, \mathrm{~V} 11=-1.196, \mathrm{~V} 13=1.122$, and V14 $=-.659$. Absolute value of $\beta$ is the highest for V11, which means that this variable has the highest level of impact on the dependent variable in an inverse way. It means, if adaptation of teaching method is good, then overall provisions designed will meet learner's need without any distortions. 


\subsection{Qualitative Data From Primary School Teachers}

Data have also been collected from 20 primary school teachers to know their convenience or inconvenience owing to digital shift of education. The method adopted was in-depth interview just to have qualitative data on their feelings and experience. There are two sets of reactions as mentioned below.

\subsubsection{Teachers Who Get Engaged in Online Classes}

Out of 20 teachers interviewed, nine teachers were taking online classes. All of them were taking classes on Cisco Webex site. Each teacher is a Class teacher of a Section. S/he was creating the Group and communicating all details of Classes of all the teachers. Although a teacher takes couple of classes daily but s/he was supposed to be on toes till the classes of all the teachers get concluded. While the classes were going on, the Principal of the school does give visits to each class at least for 5-10 minutes.

Teachers were not very comfortable as they were using the virtual mode for the first time. It was troublesome for them and was putting tremendous pressure on teachers. There were interruptions from network and audio-visuals as well. In spite of advising the students to mute their mics, teachers were feeling restlessness for unnecessary noises from the backgrounds of students. Since most of the students were accompanied by their parents, there was unexpected interventions from parents even. Since parents were tied up with the online classes, they were getting frustrated so also the teachers. Anyways, with much difficulties, teachers could accomplish their target although the outcome was yet to be ascertained.

\subsubsection{Teachers Who Communicate With Students and Their Parents Through WhatsApp/E-mail}

Out of 20 teachers interviewed, 11 teachers were interacting with students and their parents concerning delivery through WhatsApp/E-mail. Each teacher is the class teacher of a section. All the class teachers create the WhatsApp group for their respective sections. Then they add all the teachers in that group. Time table was fixed and the same was communicated through the Group. A teacher during his/her slot posts study materials, video lectures and hand-written notes, if any. Students are adivised to go through those and if they find any difficulty, they are to clarify their doubts messaging through WhatsApp. Parents found it very clumsy as many study materials come through WhatsApp and accessing all of those on a small screen is really tough and making students write all those on notebooks make them cry. Teachers receive n-numbers of queries on daily basis addressing to all of those was nearly impossible. As there was communication gap, many a times, parents/students put very silly questions like 'where to write?', 'how to write?', 'shall I write in black pen or in blue pen?', 'shall I memorize it?', etc. All these questions make the teachers frustrated.

\subsection{Data From Miscellaneous Modes}

\subsubsection{Teachers Who Were Providing Books to the Students at Their Doorstep}

As per the directions from the Government of Odisha, since students were locked down and they were not having the books and study materials, teachers were to distribute the books and study materials to the students at their doorstep. It was made for the Odia medium schools. 10 primary school teachers from Odia medium Schools were interviewed for the purpose. They expressed their anguish out of fear and self-respect. While most of the population are advised to stay home during pandemic, they are given with multiple assignments like taking care of quarantine centers and providing books to the students at their houses. They have been doing their duties in multiple fronts in normal time without any hesitation but now as there is the threat of life during Covid-19 situation, they are bit reluctant. However, they are doing the duties assigned to them but with pain and discomfort. They 
feel, while there is struggle for life, making books available to the students won't serve the purpose of not lagging behind in academics.

\subsubsection{DTH Platforms}

Some of the regional TV channels are inviting teachers from different schools and covering syllabus of different classes. The same steps are taken in English medium curriculum. However, this is time bound mode accessing which is not a problem in urban areas but the problem lies with the rural areas. In rural areas, ordinarily, power fails very often. If during DTH class timing, there is no power, the students cannot get the benefit. If one class is missed, the students may not catch the contents in the next class as it is an one-way delivery system. Experts will deliver without taking any questions to answer. Thus, effectiveness is a question mark in rural areas. However, it can be supplementary mode to get the clarity of some concepts by chance.

\section{FINDINGS}

As per the data analyzed in Section 5, it is found that:

- Provisions catered in Online Classes and WhatsApp/E-mail communications for covering the syllabus at primary education level don't meet the students' need without any distortions.

- If study materials do not meet learners' need, students and their parents won't be satisfied.

- If adaptation of teaching method is bad, the virtual learning mode won't be accepted as it is way behind what it ought to provide.

- If interaction for class discussion is bad for any reasons, e-learning platform won't be accepted.

- If In spite of no physical interaction, misunderstanding is not there, virtual learning platform will serve the purpose and will be accepted both by the students and parents.

- Teachers get engaged vehemently and poured with innumerable queries in online classes, for addressing which, they don't have patience.

- Teachers feel working like $24 \times 7$ in online classes.

- Parents get frustrated for sitting with their children for longer time.

- Students get addicted to smart phones/laptops and get tired of looking the screen for long time. Consequently, they don't find time or feel like studying after the online classes.

- Persistent interruptions in the form of network issues and disturbances owing to audio-visuals make the teachers perturbed.

- Teachers remain in tremendous pressure as they are doing it for the first time amid multiple constraints.

- Communicating through WhatsApp/E-mail for course coverage makes the parents troublesome as they have to keep trace of every document sent by the teachers and they have to make the students write from the screen which is boring for the students.

- Communication gap in WhatsApp/E-mail mode creates innumerable doubts in the minds of students and parents which they throw to the teachers for clarifications but teachers fail to address those as keeping trace of all those queries is nearly impossible.

- Teachers who are providing Books to the students at their doorstep feel low as they are to visit each student's house to distribute the books and study materials. As such, the situation is not normal. The fear of getting affected with Covid-19 virus make them to be bit reluctant.

- Teaching through DTH platform is not convenient in rural areas frequent owing power failure.

- Although intervention by cyber sexual assailants is not experienced, the fear of such attack is there in everybody's mind, particularly in the minds of the parents and teachers. 


\section{CONCLUSION}

Since the students are cut off from their study environment during pandemic, reaching out to students virtually is without doubt a welcome step and hence can be treated as a boon. However, as we analyzed the intrinsic impact of e-learning on students, parents and teachers, we could establish that it is a bane. If e-learning acts as a supplement to classroom teaching, it may have desired result and the bottlenecks stand on the way of its universalisation won't be a problem at all. But the situation during Covid-19 pandemic is completely different as students are no more a part of the physical infrastructure of the educational institutions. E-learning is now the only mode of teaching-learning. This is helping the students of higher educational institutions to some extent. Still some students are not covered under e-learning owing to the difficulties explained in the article. Making e-learning mandated for the students of primary schools has many cons to consider it as bane. By this, students are getting exposed to internet prominently and hence the risk of harming their life is very much there as they get addicted to many negative things and suffer from many health issues. Parents of students are getting affected badly as they are to sit with their children for not safeguarding them from any cyber exploitation. Since the children are to sit in front of the device's screen most of the time of the day, it has become irritating for the parents to maintain on regular basis. Thereby, they are risking the lives of their children. Teachers at primary level are usually not that comfortable with the technology required for e-learning, but to save their job, they are taking much pain to learn that and practice. In the process, they are consuming almost 15-16 hours daily to successfully conduct the online interactions with the students. In fact, some teachers feel, had it been physical classes, they would have got some time to relax in their homes after the School timing, but due to e-learning, they are not finding any time to relax in spite of staying at their home.

The feasibility issue, as mentioned in section 2, may be addressed as the economy develops or as the government provide devices and connectivity to all the students, which may be a possibility in our welfare-centred set up. But the issues related to health of the children and fear of sexual grooming of the children cannot be avoided. Thus, it is inferred that e-learning for primary school students during Covid-19 pandemic is more of a bane than a boon. 


\section{REFERENCES}

Al-Qerem, A., Alauthman, M., \& Almomani, A. (2020). IoT transaction processing through cooperative concurrency control on fog-cloud computing environment. Soft Computing, 24, 5695-5711. https://doi. org/10.1007/s00500-019-04220-y

Amo, D., Alier, M., García-Peñalvo, F. J., Fonseca, D., \& Casañ, M. J. (2020). Protected Users: A Moodle Plugin To Improve Confidentiality and Privacy Support through User Aliases. Sustainability, 2020(12), 2548. https://doi.org/10.3390/su12062548

Chen, N., Lin, K., \& Kinshuk, N. (2004). Assessment of E-Learning Satisfaction from Critical Incidents Perspective. Proceedings of the Sixth International Conference on Enterprise Information Systems, 27-34.

Etherington, M. (2008). E-Learning pedagogy in the Primary School Classroom: The McDonaldization of Education. The Australian Journal of Teacher Education, 33(5), 29-54.

Hellsten, I. (2006). The Paradox of Inform@tion Technology in Primary Schools: E-learning is new but gender patterns are old! Scandinavian Journal of Educational Research, 50(1), 1-21.

Huang, F., Sánchez-Prieto, J. C., \& Teo, T. (2020). The influence of university students' learning beliefs on their intentions to use mobile technologies in learning: a study in China and Spain. Education Tech Research Dev, 68, 3547-3565. 10.1007/s11423-020-09806-0

Stergiou, C., Psannis, K. E., Gupta, B. B., \& Ishibashi, Y. (2018). Security, privacy \& efficiency of sustainable Cloud Computing for Big Data \& IoT. Sustainable Computing: Informatics and Systems, 19, 174-184.

Sung, Y. T., Chang, K. E., \& Liu, T. Z. (2016). The effects of integrating mobile devices with teaching and learning on students' learning performance: A meta-analysis and research synthesis Computers \& Education, Volume 94, March 2016, Pages 252-275. 